\title{
Article
}

\section{Perfil metabólico, produtivo e reprodutivo de ovelhas recebendo flushing de diferentes fontes energéticas}

\author{
Gilberto de Lima Macedo Junior ${ }^{1}$, Victor Jorge Cardoso Rodrigues ${ }^{1}$, \\ Wendell Fernando Guimarães da Cruz ${ }^{1}$, Deborah Alves Ferreira ${ }^{2}$, \\ Marina Elizabeth Barbosa Andrade ${ }^{3}$
}

\begin{abstract}
RESUMO
Suplementos com níveis energéticos semelhantes podem promover diferentes perfis metabólicos e respostas reprodutivas em função dos substratos gerados na fermentação ruminal e na digestão intestinal. Neste estudo, 28 ovelhas da raça Santa Inês com peso vivo e escore de condição corporal (ECC) médios de 39,40 kg e 2,55 respectivamente, receberam dieta basal mais um dos quatro concentrados (flushing): farelo de milho, polpa cítrica, grão de soja ou caroço de algodão (tratamentos). A suplementação foi realizada a partir de três semanas antes até três semanas depois do início da estação de monta, na quantidade de $0,5 \%$ do peso vivo dos animais, na matéria seca. Foram avaliados parâmetros reprodutivos (taxa de prenhes e prolificidade) e parâmetros metabólicos (energéticos, proteicos e hepáticos), além do peso e escore de condição corporal. $\mathrm{O}$ delineamento foi ao acaso com medidas repetidas no tempo. Houve um aumento significativo dos metabólitos sanguíneos energéticos (glicose, triglicérides, colesterol, lipoproteína de muito baixa densidade (VLDL), lipoproteína de baixa densidade (LDL) e lipoproteína de alta densidade (HDL)) e proteicos (proteína total, albumina, globulina, ureia e creatinina), das enzimas gamaglutamiltransferase (GGT) e aspartato aminotransferase (AST) e do escore de condição corporal (ECC) das ovelhas após seis semanas de suplementação. Os animais recebendo concentrado contendo caroço de algodão apresentaram maiores níveis plasmáticos de colesterol, LDL, HDL, GGT e albumina e maior ECC. Os maiores níveis plasmáticos de glicose, proteínas totais e AST foram encontrados nos tratamentos farelo de milho e polpa cítrica. Não houve diferença nos índices de fertilidade e prolificidade entre os tratamentos. A suplementação influenciou os níveis séricos dos metabólitos energéticos e proteicos e elevou o ECC a níveis satisfatórios, com potencial para
\end{abstract}

\footnotetext{
${ }^{1}$ Universidade de Uberaba.

${ }^{2}$ Universidade Federal do Tocantins.

${ }^{3}$ Unesp Jaboticabal.

* Corresponding author: Rua Ceará s/n, Bloco 2D, Bairro Umuarama, Uberlândia, MG 38402-018, Brazil. Emai: gilbertomacedojr@gmail.com
} 
melhorar os índices reprodutivos na estação de monta. A resposta sobre a prenhes foi satisfatória. Contudo, a prolificidade foi baixa.

Palavras-chave: carboidratos, desempenho reprodutivo, escore corporal, fertilidade, lipídios, nutrição, Ovis aries.

\section{Introdução}

A produtividade na ovinocultura depende do desempenho produtivo e reprodutivo dos animais. O resultado do manejo reprodutivo passa pelo controle dos eventos reprodutivos (estação de monta e estação de parição), pela maximização do número de animais nascidos (aumento da taxa de ovulação e diminuição da morte embrionária), pela sobrevivência e desenvolvimento das crias (MARTIN et al., 2004).

O termo flushing é utilizado para descrever a prática utilizada por muitos produtores de ovinos, o qual consiste em aumentar a quantidade e variedade de nutrientes para ovelhas pouco tempo antes da estação de monta, a fim de aumentar a prolificidade (CLARK, 1934; SORMUNENCRISTIAN E JAUHIAINEN, 2002). Esse resultado é chamado de "efeito dinâmico" da nutrição sobre a reprodução, pois promove aumento do peso vivo e do escore de condição corporal dos animais em um curto espaço de tempo (SCARAMUZZI et al., 2006).

Em ovelhas, o balanço energético positivo causa aumento das concentrações plasmáticas de insulina e leptina, com maior da captação de glicose, que pode estar associado com elevação da foliculogênese e taxa de ovulação (SCARAMUZZI et al., 2006). Entretanto, suplementos com níveis energéticos semelhantes podem variar suas respostas em função dos substratos gerados na fermentação ruminal e na digestão intestinal.

Os lipídios, além de melhorarem o balanço energético, podem atuar na esteroidogênese, seja por meio do aumento da produção de progesterona pelas células luteais, devido à maior circulação de colesterol, por meio do 
aumento do tempo de vida do corpo lúteo, devido a elevações das concentrações de ácido linoleico e linolênico que deprimem a PGF2 $\alpha$ ou por meio da redução do clearance da progesterona e aumento da sua meia vida plasmática (STAPLES et al., 1998).

Na década de 70, o perfil metabólico (energético e proteico) passou a ser usado como ferramenta zootécnica para auxiliar na avaliação do desempenho produtivo e reprodutivo em animais de produção (PEIXOTO E OSÓRIO, 2007).

Dessa forma, o objetivo do presente estudo foi comparar o efeito da suplementação com diferentes fontes energéticas (farelo de milho, polpa cítrica, grão de soja ou caroço de algodão) para realização do flushing em ovelhas Santa Inês sobre o perfil metabólico e desempenho reprodutivo.

\section{Material e Métodos}

O experimento foi realizado na Fazenda Experimental Capim Branco da Universidade Federal de Uberlândia, no município de Uberlândia, Minas Gerais, nos meses de setembro a dezembro no ano de 2011. CEUA 134/11. Foram utilizadas 28 ovelhas adultas (acima de três anos) da raça Santa Inês, com peso vivo e escore de condição corporal (ECC) médios de 39,40 kg e 2,55 respectivamente, ao início do período experimental. Os animais foram alojados em baias coletivas, com piso ripado (contendo bebedouro, comedouro e saleiro) e recebiam dieta basal composta de silagem de milho (equivalente a $3,5 \%$ do peso vivo médio dos animais) e acrescida do concentrado experimental, contendo farelo de milho e farelo de soja como alimentos básicos. Nesses concentrados foram incluídos os seguintes ingredientes para compor os tratamentos, conforme a tabela 1: polpa cítrica, grão de soja e caroço de algodão.

Os concentrados experimentais eram isonitrogenados e foram fornecidos três semanas antes até três semanas depois do início da estação 
de monta, na quantidade de $0,5 \%$ do peso vivo (média do peso vivo da baia), na matéria seca. Durante todo período experimental, os animais tiveram acesso livre ao sal mineral específico para ovinos. A tabela 1 apresenta a composição percentual de ingredientes e composição bromatológica dos concentrados experimentais e da silagem de milho utilizados.

Tabela 1. Composição percentual de ingredientes e composição bromatológica dos concentrados experimentais contendo farelo de milho, polpa cítrica, grão de soja ou caroço de algodão e da silagem de milho.

\begin{tabular}{|c|c|c|c|c|c|}
\hline \multirow[t]{2}{*}{ Ingrediente (\% da MS) } & \multicolumn{4}{|c|}{ Concentrados experimentais } & \multirow{2}{*}{$\begin{array}{c}\text { Volumoso } \\
\begin{array}{c}\text { Silagem de } \\
\text { milho }\end{array}\end{array}$} \\
\hline & $\begin{array}{c}\text { Farelo de } \\
\text { Milho }\end{array}$ & $\begin{array}{c}\text { Polpa } \\
\text { Cítrica } \\
\end{array}$ & $\begin{array}{c}\text { Grão de } \\
\text { Soja }\end{array}$ & $\begin{array}{c}\text { Caroço de } \\
\text { Algodão }\end{array}$ & \\
\hline Polpa cítrica & - & 29,95 & - & - & - \\
\hline Caroço de algodão & - & - & - & 14,25 & - \\
\hline Farelo de milho & 75,63 & 45,00 & 73,18 & 66,85 & - \\
\hline Grão de soja & - & - & 21,81 & - & - \\
\hline Farelo de soja & 24,37 & 25,05 & 5,0 & 18,90 & - \\
\hline \multicolumn{6}{|c|}{ Composição Bromatológica } \\
\hline \multicolumn{6}{|l|}{ Nutrientes (\% da MS) } \\
\hline Matéria seca ${ }^{1}$ & 90,24 & 90,37 & 90,46 & 90,52 & 33,46 \\
\hline Proteína bruta & 15,58 & 15,30 & 15,62 & 15,23 & 6,54 \\
\hline Extrato etéreo & 3,19 & 3,03 & 18,56 & 5,38 & 1,51 \\
\hline Fibra em detergente neutro & 12,14 & 11,93 & 13,31 & 13,65 & 52,33 \\
\hline Fibra em detergente ácido & 4,82 & 5,88 & 5,70 & 6,93 & 30,19 \\
\hline Energia Bruta ${ }^{2}$ & 4012 & 3907 & 4133 & 4192 & 3830 \\
\hline
\end{tabular}

${ }^{1}$ Matéria natural; ${ }^{2} \mathrm{Kcal} / \mathrm{kg}$

As ovelhas foram pesadas semanalmente e o escore de condição corporal foi determinado no início, meio e final do período experimental, de acordo com Russel et al. (1969).

A avaliação do perfil bioquímico sanguíneo foi realizada no início (dia 0) e final (dia 60) do período experimental. A coleta do sangue para glicemia foi obtida em quatro períodos do dia: 8h (antes da primeira refeição), 11h, 14h e 17h. Após a última coleta, foi ofertada a segunda refeição aos animais. O sangue foi coletado diretamente na veia jugular por venopunção com auxílio de vacutainer e acondicionados em tubos de ensaio sem 
anticoagulante com capacidade de $10 \mathrm{~mL}$ para a avaliação do soro sanguíneo e de $4 \mathrm{~mL}$ com fluoreto de sódio para avaliação do plasma.

Para obtenção do soro sanguíneo, os tubos coletores foram centrifugados a 3500 rotações por minuto, por dez minutos. As alíquotas de soro foram, então, mantidas congeladas a $-18^{\circ} \mathrm{C}$ em criotubos até o momento das análises laboratoriais, em que foram medidas as concentrações de glicose, colesterol, triglicérides, lipoproteína de alta densidade (HDL), lipoproteína de muito baixa densidade (VLDL), lipoproteína de baixa densidade (LDL), ureia, creatinina, proteína total, albumina, globulinas, aspartato aminotransferase (AST) e gamaglutamiltransferase (GGT), utilizando-se kits Labtest ${ }^{\circledR}$ no aparelho Bioplus ${ }^{\circledR} 2000$.

Para realização das coberturas, as ovelhas foram sincronizadas com $\mathrm{Cidr}^{\circledR}$ em protocolo de nove dias. Durante sete dias, os animais ficaram com o implante de progesterona na vagina. No sétimo dia, retirou-se o implante e foi feita aplicação do $\operatorname{Sincrocio}^{\circledR}(0,5 \mathrm{~mL} / \mathrm{cab})$ mais o Folligon $(1,0 \mathrm{~mL} / \mathrm{cab})$. Após as coberturas (monta natural com observação visual), esperou-se 30 dias e foi feito exame de ultrassonografia para detecção da gestação e prolificidade.

O delineamento foi inteiramente ao acaso com medidas repetidas no tempo, tendo sete repetições por tratamento. Para análise dos efeitos do período e do tratamento, foi utilizado o teste de Tukey a $5 \%$ de probabilidade. Para os parâmetros prolificidade e fertilidade, foi usado o teste de Fisher exato. Para a avaliação da condição corporal, utilizou-se estatística não paramétrica.

\section{Resultados e Discussão}

Houve aumento significativo dos valores dos metabólitos sanguíneos energéticos (glicemia e lipidograma) das ovelhas recebendo concentrado experimental contendo diferentes fontes energéticas entre o início e o final do período experimental (tabela 2). Esse resultado revela que a 
suplementação energética, na quantidade de $0,5 \%$ do peso vivo, durante seis semanas, aumentou a disponibilidade de energia e promoveu alteração da condição metabólica das ovelhas com escore de condição corporal inicial de 2,55 .

Tabela 2. Valores médios dos metabólitos energéticos $(\mathrm{mg} / \mathrm{dL})$ de ovelhas recebendo suplementação energética (flushing) com diferentes concentrados.

\begin{tabular}{lcccccc}
\hline Metabólitos (mg/dL) & \multicolumn{7}{c}{} \\
\hline Período experimental & Glicose & Triglicérides & Colesterol & VLDL & LDL & HDL \\
Início & $45,36 \mathrm{~b}$ & $13,46 \mathrm{~b}$ & $56,40 \mathrm{~b}$ & $2,69 \mathrm{~b}$ & $16,86 \mathrm{~b}$ & $37,85 \mathrm{~b}$ \\
Final & $61,80 \mathrm{a}$ & $19,48 \mathrm{a}$ & $73,00 \mathrm{a}$ & $3,89 \mathrm{a}$ & $25,53 \mathrm{a}$ & $44,46 \mathrm{a}$ \\
\hline Tratamentos & Glicose & Triglicérides & Colesterol & VLDL & LDL & HDL \\
\hline Farelo de Milho (FM) & $56,10 \mathrm{a}$ & 15,16 & $51,68 \mathrm{c}$ & 3,03 & $17,48 \mathrm{~b}$ & $33,75 \mathrm{c}$ \\
Polpa Cítrica (PC) & $54,52 \mathrm{ab}$ & 17,44 & $60,48 \mathrm{~b}$ & 3,48 & $18,26 \mathrm{~b}$ & $39,37 \mathrm{~b}$ \\
Grão de Soja (GS) & $51,01 \mathrm{c}$ & 14,97 & $60,30 \mathrm{~b}$ & 2,99 & $16,84 \mathrm{~b}$ & $41,22 \mathrm{~b}$ \\
Caroço de Algodão (CA) & $52,46 \mathrm{bc}$ & 17,31 & $81,71 \mathrm{a}$ & 3,05 & $30,13 \mathrm{a}$ & $48,12 \mathrm{a}$ \\
\hline Média geral & 53,58 & 17,73 & 66,02 & 3,54 & 23,30 & 41,93 \\
CV & 15,81 & 55,18 & 22,33 & 55,17 & 42,87 & 29,33 \\
\hline Referência* & $50-80$ & & $52-76$ & & &
\end{tabular}

*Kaneko et al. (2008); CV - coeficiente de variação. Médias seguidas por letras diferentes na coluna diferem estatisticamente entre si $(\mathrm{P}<0,05)$

Houve aumento na glicemia, de 45,36 para $61,80 \mathrm{mg} / \mathrm{dL}$, representando mais de 35\% de elevação da glicose plasmática após seis semanas de flushing (tabela 2). Provavelmente, essa suplementação aumentou a produção de ácidos graxos voláteis totais (AGVs) e propionato no rúmen. Em ruminantes, a maior parte da glicose plasmática é oriunda da gliconeogênese hepática que utiliza o propionato produzido pelos microrganismos ruminais como substrato. Em estudo realizado por $\mathrm{Li}$ et al. (2013), o maior consumo de energia por vacas leiteiras promoveu aumento na quantidade de precursores gliconeogênicos que culminou com a maior produção de RNAm para as enzimas fosfoenolpiruvato carboxiquinase (PEPCK) e glicose-6-fosfatase (G6P) no tecido hepático. Destaca-se na tabela 1 que o farelo de milho esteve presente em todos os concentrados, favorecendo a formação de ácido propiônico no rumem.

A suplementação energética das ovelhas promoveu aumento dos triglicérides, colesterol, VLDL, LDL e HDL plasmáticos (tabela 2) após seis semanas de suplementação (três semanas antes da cobertura e três semanas após a 
cobertura). Em ruminantes, além do tecido adiposo, os triglicérides são sintetizados pelas células do intestino delgado a partir dos ácidos graxos oriundos da dieta e por elas absorvidos (reesterificação), para que sejam transportados na circulação sanguínea sob a forma de lipoproteínas (quilomícrons e VLDL). Em dietas contendo suplementação lipídica, ocorre aumento da produção de colesterol a partir do acetato, pelas células do intestino delgado, a fim de conduzir essa gordura absorvida (NESTEL et al., 1978), já que o colesterol é fundamental na formação das lipoproteínas. O colesterol também é precursor da síntese de hormônios esteróides, vitamina D e sais biliares, e participa da formação das membranas celulares. Os animais desse estudo tiveram concentração de colesterol sanguínea suficiente para síntese dessas substâncias e para desempenhar funções essenciais no organismo do animal, uma vez que as concentrações desse metabólito ficaram dentro dos valores considerados referência para a espécie ovina, principalmente no tratamento contendo caroço de algodão. Dessa maneira, observa-se que houve melhora na resposta energética das ovelhas entre o início e fim do período experimental, evidenciando que o flushing foi eficiente na melhora do status energético dos animais.

A LDL plasmática é oriunda da degradação intravascular da VLDL e está relacionada com o transporte de colesterol para os tecidos periféricos (BAUCHART, 1993). A HDL é a principal lipoproteína plasmática em ruminantes e é responsável pela condução reversa do colesterol dos tecidos periféricos ao fígado. No presente estudo, os ingredientes lipídicos proporcionaram maior disponibilidade de ácidos graxos no intestino delgado, induzindo a necessidade de aumentar a síntese do colesterol para a formação das lipoproteínas e seu transporte na forma de triglicérides.

$\mathrm{Na}$ avaliação da glicemia em função de cada tratamento (tabela 2), observou-se que aqueles com predominância de alimentos ricos em carboidratos não fibrosos (CNFs) (farelo de milho (FM) e polpa cítrica (PC)) promoveram maiores valores que aqueles que continham ingredientes lipídicos em sua composição (grão de soja (GS) e caroço de algodão (CA)) (tabela 2). Os CNFs apresentam alta degradabilidade ruminal e, consequentemente, elevada produção de AGVs. Além disso, a energia gerada no rúmen pela degradação dos carboidratos promove maior produção de proteína microbiana, que também fornecerá precursores (aminoácidos 
glicogênicos) para a síntese de glicose hepática e renal (REYNOLDS, 2006). Embora a polpa cítrica apresente em sua composição a pectina, que não tem o mesmo potencial para produção de propionato como o amido presente no milho, sua utilização no concentrado substituiu o milho em 39,6\%, não sendo suficiente para alterar o perfil glicêmico. Já os lipídios não fornecem energia para o crescimento microbiano ruminal (MACZULAK et al., 1981). Portanto, esses nutrientes não promovem a produção de AGVs e proteína microbiana e, dessa forma, os animais recebendo concentrados contendo lipídios apresentam menores concentrações de glicose plasmática.

Houve efeito significativo do tratamento nas concentrações plasmáticas de colesterol, LDL e HDL $(\mathrm{P}<0,05)$ (tabela 2$)$. Os maiores valores foram observados nos animais que receberam o tratamento CA. Provavelmente o maior valor de extrato etéreo nesse concentrado (tabela 1) estimulou a maior produção de colesterol para a formação das lipoproteínas e transporte dos lipídios absorvidos. Segundo Staples et al. (1998), alimentos que são fontes lipídicas, como os grão de soja e o caroço de algodão, podem aumentar os níveis séricos de colesterol e triglicérides. Por conseguinte, fornecem substrato para síntese de progesterona e estrógeno a partir do colesterol. $\mathrm{O}$ aumento na HDL com a presença de fontes lipídicas no concentrado é interessante, pois essa lipoproteína é altamente carreadora de lipídeos no organismo, melhorando a eficiência de uso do colesterol e triglicerídeos. Assim, infere-se que o flushing elevou a taxa metabólica dos animais, possivelmente elevando a atividade hepática.

As enzimas AST e GGT, indicadoras de lesões hepáticas, aumentaram nas ovelhas entre o período inicial e final (tabela 3). Os valores mantiveram-se dentro do estabelecido como normal por Kaneko et al. (2008), indicando que não houve lesão no fígado dos animais, ainda que houvesse diferença nos valores entre os tratamentos. Infere-se que esse aumento tenha sido provocado pela melhora na nutrição dos animais, o que acabou tendo mais nutrientes para serem metabolizados no fígado, como já supracitado. 
Tabela 3. Teores séricos das enzimas aspartato aminotransferase (AST) e gamaglutamiltransferase (GGT) de ovelhas recebendo suplementação energética (flushing) com diferentes concentrados.

\begin{tabular}{lcc}
\hline & GGT (U/L) & AST (U/L) \\
\hline Período experimental & & \\
Início & $37,83 \mathrm{~b}$ & $71,58 \mathrm{~b}$ \\
Final & $41,65 \mathrm{a}$ & $80,69 \mathrm{a}$ \\
\hline Tratamentos & GGT (U/L) & AST (U/L) \\
\hline Farelo de Milho (FM) & $39,12 \mathrm{~b}$ & $95,95 \mathrm{a}$ \\
Polpa Cítrica (PC) & $38,23 \mathrm{bc}$ & $79,84 \mathrm{~b}$ \\
Grão de Soja (GS) & $33,73 \mathrm{c}$ & $62,05 \mathrm{c}$ \\
Caroço de Algodão (CA) & $46,65 \mathrm{a}$ & $66,62 \mathrm{c}$ \\
\hline Média geral & 40,60 & 77,32 \\
CV & 30,80 & 34,09 \\
\hline Referência* & $20-52$ & $60-280$ \\
\hline
\end{tabular}

*Kaneko et al. (2008); CV - coeficiente de variação. Médias seguidas por letras diferentes na coluna diferem estatisticamente entre si $(\mathrm{P}<0,05)$

A enzima aspartato aminotransferase (AST), quando identificada acima das concentrações consideradas normais, indica que o animal pode desenvolver lesão hepato-celular secundária, oriunda da excessiva mobilização lipídica. No entanto, no presente estudo, as concentrações de AST estiveram dentro do intervalo considerado normal para a espécie, o que indica que esses animais não desenvolveram lesão hepática. Destaca-se que os animais suplementados somente com farelo de milho e farelo de soja apresentaram o maior valor. A gamaglutamiltransferase (GGT) é uma enzima presente na membrana celular de diversos tecidos como fígado, rins, pâncreas e intestino, porém, a maior concentração dessa enzima é nas células tubulares renais e no epitélio dos ductos biliares. Sua atividade é relativamente alta no fígado de bovinos, ovinos e caprinos. Aumentos séricos da GGT são verificados principalmente em animais com desordens hepáticas (Kaneko et al., 2008). No presente estudo, os valores de GGT permaneceram dentro do intervalo, considerado normal para espécie, o que evidencia que esses animais não desenvolveram lesão hepática. Destacase que os animais do tratamento caroço de algodão apresentaram o maior valor dessa enzima hepática.

Verificou-se aumento da concentração dos metabólitos proteicos no soro sanguíneo das ovelhas ao final do período experimental $(\mathrm{P}<0,05)$ (tabela 4). Os maiores valores de proteínas totais, albuminas e globulinas sugerem que o flushing 
promoveu maior aporte de proteína metabolizável aos animais. Esse aumento pode ter sido via fornecimento de proteína degradável no rúmen e carboidratos fermentáveis para produção de proteína microbiana e aumento da proteína não degradável no rúmen, oriundos da suplementação concentrada, principalmente vinda do caroço de algodão (CA).

Observa-se aumento nos valores de ureia sanguínea após seis semanas de suplementação das ovelhas. Os lipídios não fornecem energia para o metabolismo microbiano ruminal. Dessa forma, os concentrados contendo grãos de soja e caroço de algodão podem ter reduzido o aporte energético para o crescimento microbiano, reduzindo a utilização das fontes de nitrogênio, que então foram absorvidas em maior quantidade na forma de amônia, uma vez que todos os concentrados eram isonitrogenados. A amônia absorvida no rúmen é convertida em ureia pelo fígado e rins. A ureia é sintetizada no fígado em quantidades proporcionais à concentração de amônia produzida no rúmen, que é diretamente relacionada com os níveis proteicos da ração e da relação energia e proteína da dieta.

Os níveis de creatinina aumentaram ao final do período experimental, entretanto, não se apresentaram acima dos valores considerados normais para a espécie ovina. Elevados valores de creatinina, acima do normal, indicam lesão renal. Neste estudo, o aumento da creatinina pode ter ocorrido devido ao aumento do escore de condição corporal dos animais após a suplementação, com aumento da massa muscular e liberação de creatinina na corrente sanguínea. 
Tabela 4. Valores médios dos metabólitos proteicos de ovelhas recebendo suplementação energética (flushing) com diferentes concentrados.

\begin{tabular}{|c|c|c|c|c|c|c|}
\hline \multicolumn{7}{|l|}{ Metabólitos } \\
\hline Periodo experimental & $\begin{array}{c}\text { Proteína } \\
\text { total } \\
(\mathrm{g} / \mathrm{dL}) \\
\end{array}$ & $\begin{array}{l}\text { Albumina } \\
(\mathrm{g} / \mathrm{dL})\end{array}$ & $\begin{array}{l}\text { Globulina } \\
\text { (g/dL) }\end{array}$ & $\mathrm{A} / \mathrm{G}$ & $\begin{array}{c}\text { Ureia } \\
(\mathrm{mg} / \mathrm{dL})\end{array}$ & $\begin{array}{c}\text { Creatinina } \\
(\mathrm{mg} / \mathrm{dL})\end{array}$ \\
\hline Início & $6,96 \mathrm{~b}$ & $1,93 \mathrm{~b}$ & $5,02 \mathrm{~b}$ & 0,39 & $27,36 b$ & $0,87 \mathrm{~b}$ \\
\hline Final & $8,64 \mathrm{a}$ & $2,50 \mathrm{a}$ & $6,13 \mathrm{a}$ & 0,41 & $40,65 a$ & $1,02 \mathrm{a}$ \\
\hline Tratamentos & $\begin{array}{c}\text { Proteína } \\
\text { total } \\
(\mathrm{g} / \mathrm{dL}) \\
\end{array}$ & $\begin{array}{l}\text { Albumina } \\
(\mathrm{g} / \mathrm{dL})\end{array}$ & $\begin{array}{l}\text { Globulina } \\
\text { (g/dL) }\end{array}$ & $\mathrm{A} / \mathrm{G}$ & $\begin{array}{c}\text { Ureia } \\
\text { (mg/dL) }\end{array}$ & $\begin{array}{l}\text { Creatinina } \\
(\mathrm{mg} / \mathrm{dL})\end{array}$ \\
\hline Farelo de Milho (FM) & $7,89 \mathrm{a}$ & $1,89 \mathrm{c}$ & $5,59 \mathrm{~b}$ & $0,41 b$ & $24,92 \mathrm{c}$ & $1,04 \mathrm{a}$ \\
\hline Polpa Cítrica (PC) & $7,97 \mathrm{a}$ & $2,03 \mathrm{c}$ & $5,94 \mathrm{a}$ & $0,35 c$ & $29,05 \mathrm{bc}$ & $0,99 \mathrm{ab}$ \\
\hline Grão de Soja (GS) & $7,00 \mathrm{~b}$ & $2,30 \mathrm{~b}$ & $5,11 \mathrm{c}$ & $0,35 \mathrm{c}$ & $46,06 \mathrm{a}$ & $0,89 \mathrm{c}$ \\
\hline Caroço de Algodão (CA) & $8,01 \mathrm{a}$ & $2,54 \mathrm{a}$ & $5,46 \mathrm{~b}$ & $0,47 \mathrm{a}$ & $33,93 b$ & $0,91 \mathrm{c}$ \\
\hline Média geral & 7,73 & 2,19 & 5,53 & 0,40 & 33,98 & 0,97 \\
\hline $\mathrm{CV}$ & 11,41 & 16,18 & 14,25 & 22,44 & 49,78 & 30,65 \\
\hline Referência* & $6-7,9$ & $2,4-3$ & $3,5-5,7$ & $\begin{array}{c}0,42- \\
0,76 \\
\end{array}$ & $17-42$ & $1,2-1,9$ \\
\hline
\end{tabular}

*Kaneko et al. (2008); CV - coeficiente de variação. Médias seguidas por letras diferentes na coluna diferem estatisticamente entre si $(\mathrm{P}<0,05)$

Os animais que receberam o tratamento grão de soja (GS) como principal ingrediente apresentaram menores valores de proteínas totais e maiores valores de ureia circulantes em relação àqueles que receberam o tratamento CA. Segundo Villaça et al. (1999), a digestibilidade in vitro da proteína bruta de dietas contendo caroço de algodão foi menor em relação às dietas a base de milho e farelo de soja (controle) ou contendo grãos de soja. Além disso, o grão de soja apresenta maior fração A da proteína bruta e maior taxa de degradação ruminal da proteína em relação ao caroço de algodão (VALADARES FILHO et al., 2006). Dessa forma, pode ser que a soja grão tenha apresentado maior degradabilidade ruminal da fração proteica e, por conseguinte, maiores teores de amônia ruminal e ureia plasmática, já que nos dois concentrados o aporte de carboidratos não fibrosos para síntese de proteína microbiana foi reduzido pelo acréscimo da fração lipídica. Embora o caroço de algodão apresente menor degradabilidade ruminal da proteína, a menor taxa de degradação da fração potencialmente degradável pode ter proporcionado melhor sincronização da 
proteína e da energia disponível para síntese de proteína microbiana e ter, então, apresentado maior valor de proteína total e albumina.

Houve um aumento do escore de condição corporal (ECC) das ovelhas com a suplementação energética $(\mathrm{P}<0,05)$ (tabela 5). Esse resultado deve-se ao aumento do consumo de energia e proteína por meio dos concentrados. De acordo com Downing e Scaramuzzi (1991), o flushing inclui o aumento no consumo de nutrientes com consequente aumento do ECC. Desse modo, pode-se dizer que os suplementos concentrados utilizados neste estudo, na quantidade de $0,5 \%$ do peso vivo dos animais, podem ser aplicados com essa finalidade. Há "efeito dinâmico" em que o aumento do peso vivo e da condição corporal durante um curto período, como o de três semanas antes do início da estação de monta, pode aumentar a taxa ovulatória (COOP, 1966; SCARAMUZZI et al., 2006), taxa de concepção, número de cordeiros nascidos por ovelha exposta e o número de cordeiros desmamados por ovelha exposta (VATANKHAH et al., 2012).

Vatankhah et al. (2012) avaliaram as características reprodutivas (taxa de concepção, número de cordeiros nascidos, número de cordeiros desmamados) e produtivas (peso total dos cordeiros ao nascimento por ovelha exposta, peso total de cordeiros desmamados por ovelha exposta) de ovelhas Lori-Bakhtiari com diferentes ECCs antes da monta e verificaram que as ovelhas com ECC entre 3,0 e 3,5 apresentaram melhor desempenho em relação àquelas com ECC maiores ou menores. Abdel-Mageed (2009) observou que o desempenho reprodutivo (período de serviço, número e peso de cordeiros nascidos, taxa de aborto) de ovelhas Ossimi foi superior quando apresentaram ECC entre 2,5 e 3,0 ao início da estação de monta. Salles e Eloy (2005) preconizam que os animais selecionados para a estação de monta estejam com ECC entre 2,0 e 2,5 para que, após receberem o flushing apresentem ECC entre 3,0 e 3,5 ao iniciarem a estação de acasalamento. Pode-se inferir que os animais submetidos ao flushing alcançaram ECC recomendado para o acasalamento (3,13 ao início da estação). 
Tabela 5. Peso corporal e escore de condição corporal de ovelhas recebendo suplementação energética (flushing) com diferentes concentrados.

\begin{tabular}{lll}
\hline Parâmetros & & \\
\hline Período experimental & Escore de Condição Corporal & Peso Corporal (kg) \\
Início & $2,55 \mathrm{c}$ & 39,42 \\
Meio & $3,13 \mathrm{~b}$ & 45,00 \\
Final & $3,57 \mathrm{a}$ & 47,48 \\
\hline Tratamentos & Escore de Condição Corporal & Peso Corporal (kg) \\
Farelo de Milho (FM) & $3,19 \mathrm{~b}$ & $44,74 \mathrm{ab}$ \\
Polpa Cítrica (PC) & $2,66 \mathrm{c}$ & $42,80 \mathrm{~b}$ \\
Grão de Soja (GS) & $3,00 \mathrm{~b}$ & $43,34 \mathrm{ab}$ \\
Caroço de Algodão (CA) & $3,55 \mathrm{a}$ & $46,17 \mathrm{a}$ \\
\hline Média geral & 3,08 & 44,22 \\
Coeficiente de variação & 13,23 & 11,96 \\
\hline *Médias seguidas por letras diferentes na coluna diferem estatisticamente entre si $(\mathrm{P}<0,05)$
\end{tabular}

Não houve diferença entre o peso corporal inicial e final dos animais após o flushing (P>0,05), mesmo havendo diferença no ECC (tabela 5). De acordo com Vatankhah et al. (2012), diferenças no tamanho e estrutura esquelética das ovelhas podem reduzir a correlação entre esses dois parâmetros e que, portanto, o peso vivo não deve ser utilizado como indicador de adiposidade dos animais, e sim o ECC.

Os animais recebendo o tratamento CA apresentaram maior ECC em relação aos demais. $\mathrm{O}$ menor ECC foi observado nas ovelhas recebendo concentrado contendo polpa cítrica $(\mathrm{P}<0,05)$ (tabela 5$)$. Esse resultado pode ser devido ao maior aporte de lipídios oriundos desse ingrediente para armazenamento no tecido adiposo, já que nesse grupo também foram observados maiores valores de colesterol, LDL e HDL plasmáticos (tabela 2). A polpa cítrica apresenta fermentação ruminal acética, com menor eficiência energética ruminal, devido a maior produção de metano, em relação a dietas propiônicas, como aquelas a base de milho, o que pode ter reduzido o aporte energético para acúmulo de tecido muscular e adiposo nesse grupo.

Não houve diferença sobre a fertilidade e prolificidade das ovelhas (tabela 6). A média do escore de condição corporal (ECC) no início do experimento era de 2,55 e alcançou valor de 3,13 ao início da estação de acasalamento e 3,57 três semanas depois. Esses parâmetros são considerados adequados para ovelhas em estação de monta (SALLES E ELOY, 2005; ABDEL-MAGEED, 2009). O ECC 
adequado nos diferentes grupos associado ao reduzido número de animais avaliado neste estudo podem ser responsáveis por não haver diferença entre os tratamentos.

Tabela 6. Índices reprodutivos (fertilidade e prolificidade) de ovelhas recebendo suplementação energética (flushing) contendo como principal ingrediente farelo de milho, polpa cítrica, grão de soja ou caroço de algodão.

\begin{tabular}{llllll}
\hline & \multicolumn{2}{l}{ Parâmetros reprodutivos } & & \\
\cline { 2 - 5 } & Fertilidade & & $\begin{array}{l}\text { Prolificidade } \\
\text { nascidos/ovelha) }\end{array}$ & $\left(\mathrm{n}^{\mathbf{0}}\right.$ & animais \\
\cline { 2 - 5 } Tratamentos & Positivo & Negativo & 0 & 1 & 2 \\
Farelo de Milho (FM) & $57,14 \%$ & $42,86 \%$ & $42,86 \%$ & $42,86 \%$ & $14,29 \%$ \\
Polpa Cítrica (PC) & $100,00 \%$ & $0,00 \%$ & $0,00 \%$ & $71,43 \%$ & $28,57 \%$ \\
Grão de Soja (GS) & $66,67 \%$ & $33,33 \%$ & $33,33 \%$ & $50,00 \%$ & $16,67 \%$ \\
Caroço de Algodão (CA) & $85,71 \%$ & $14,29 \%$ & $14,29 \%$ & $57,14 \%$ & $28,57 \%$ \\
\hline
\end{tabular}

Considerando-se todos os grupos, a fertilidade foi de 78,57\%, a prolificidade (número de cordeiros nascidos por ovelha parida) foi de 1,27 e a prolificidade por ovelha exposta (número de cordeiros nascidos por ovelha exposta ao macho) foi de 1,0. Podemos considerar que a taxa de fertilidade foi de média para alta. Contudo, foram baixos os valores ligados à prolificidade dos animais. $\mathrm{O}$ fato das ovelhas terem mais de três anos pode ter contribuído para esses valores. Contudo, o flushing foi eficiente na taxa de prenhes. Esperava-se melhores resultados de prolificidade com os dados obtidos tanto no metabolismo energético quanto proteico das ovelhas. Como já supracitado, o pequeno número de ovelhas por tratamento pode ter sido a causa dessa igualdade.

\section{CONCLUSÃO}

A suplementação energético proteica, contendo ingredientes ricos em carboidratos ou lipídios, na base de 0,5\% do peso vivo, para ovelhas Santa Inês três semanas antes até três semanas depois do início da estação de monta, influenciou os níveis séricos dos metabólitos energéticos e proteicos e 
elevou o ECC a níveis satisfatórios, com potencial para melhorar os índices reprodutivos na estação de monta.

O caroço de algodão promoveu melhores respostas dentre todos os demais alimentos utilizados, evidenciando grande potencial de uso em ovelhas próximas da época de estação de monta.

\title{
Metabolic, productive and reproductive profile of ewes receiving flushing supplementation with different energy sources
}

\begin{abstract}
:
Supplements with similar energetic levels may promote different metabolic and reproductive responses as a function of the substrates produced in ruminal fermentation and intestinal digestion. In the present study, 28 Santa Ines ewes with a mean body weight and body condition score (BCS) of $39.40 \mathrm{~kg}$ and 2.55, respectively, were fed a basal diet with one of four flushing supplementation sources: corn meal, citrus pulp, soybean or cottonseed. The supplementation started three weeks before until three weeks after the start of mating season, at $0.5 \%$ of the live weight on a dry matter basis. The following reproductive parameters (pregnancy rate and prolificacy) and metabolic parameters (energy, protein and liver), besides weight and body condition score were evaluated. The design was completely randomized with repeated measures in time. There was a significant increase in energetic metabolites (glucose, triglycerides, cholesterol, very low density lipoprotein - VLDL, low density lipoprotein LDL and high density lipoprotein - HDL), protein metabolites (total protein, albumin, globulin, urea and creatinine), gamma glutamyl transferase - GGT and aspartate aminotransferase - AST enzymes and body condition score (BCS) of ewes after six weeks of supplementation. The animals fed concentrate containing cottonseed had higher plasmatic levels of cholesterol, LDL, HDL, GGT and albumin and higher BCS. The highest glucose, total proteins and AST levels were found in ewes fed corn meal and citrus pulp. There was no difference in fertility and prolificacy parameters between treatments. Supplementation influenced serum levels of energy and protein metabolites and elevated BCS to satisfactory levels, with potential to improve reproductive parameters at the breeding season. The response to pregnancy was satisfactory. However, prolificity was low.

Keywords: carbohydrate; lipids; nutrition; reproductive performance; Ovis aries.
\end{abstract}




\section{Referências}

ABDEL-MAGEED, I. Body condition scoring of local Ossimi ewes at mating and its impact on fertility and prolificacy. Egyptian Journal of Sheep \& Goat Sciences, v. 4, n. 1, p. 37-44, 2009.

BAUCHART, D. Lipid absorption and transport in ruminants. Journal of Dairy Science, v. 76, n. 12, p. 3864-3881,1993.

CLARK, R. T. Studies on the phisyology of reproduction in the sheep. I. The ovulation rate of the ewe as affected by the plane of nutrition. The Anatomical Record, v.60, n. 2, p. 125-134, 1934.

COOP, I. E. Effect of flushing on reproductive performance of ewes. Journal of Agricultural Science, v.67, n. 3, p. 305-323, 1966.

DOWNING, J. A.; SCARAMUZZI, R. J. Nutrient effects on ovulation rate, ovarian function and the secretion of gonadotrophic and metabolic hormones in sheep. Journal of Reproduction and Fertility, supl. 43, p. 209-227, 1991.

KANEKO, J. J.; HARVEY, J. W.; BRUSS, M. L. Clinical Biochemistry of Domestic Animals. 6. ed. San Diego: Academic Press. 2008. 916p.

LI, W. Q; BU, D. P.; WANG, J. Q.; NAN, X. M.; SUN, P.; ZHOU, L.Y. Effect of two different diets on liver gene expression associated with glucose metabolism in dairy cows. Livestock Science, v. 158, n. 1-3, p.223-229, 2013.

MACZULAK, A. E.; DEHORITY, B. A.; PALMQUIST, D.L. Effects of long-chain fatty acids on growth of rumen bacteria. Applied and Environmental Microbiology, v. 42, n. 5, p. 856-862, 1981.

MARTIN, G. B.; MILTON, J. T. B.; DAVIDSON, R.H.; BANCHERO HUNZICKER, G. E.; LINDSAY, D. R.; BLACHE, D. Natural methods for increasing reproductive 
efficiency in small ruminants. Animal Reproduction Science, v. 82-83, p. 231$246,2004$.

NESTEL, P. J.; POYSER, A.; HOOD, R. L. The effect of dietary fat supplements on cholesterol metabolism in ruminants. Journal of Lipid Research, v.19, n.7, p. 899-909, 1978.

PEIXOTO, L. A. O.; OSÓRIO, M. T. M. Perfil metabólico proteico e energético na avaliação do desempenho reprodutivo em ruminantes. Revista Brasileira de Agrociência, v.13, n.3, p. 299-304, 2007.

REYNOLDS, C. K. Production and metabolic effects of site of starch digestion in dairy cattle. Animal Feed Science and Technology, v. 130, n. 1-2 , p. 78-94, 2006.

RUSSEL, A. J. F.; DONEY, J. M.; GUNN, R. G. Subjective assessment of body fat in live sheep. Journal Agricultural Science, v.72, n. 3, p.451-454, 1969.

SALLES, H. O.; ELOY, A. X. Sistema de produção de caprinos e ovinos de corte para o nordeste brasileiro: Manejo reprodutivo. Disponível em: < http://sistemasdeproducao.cnptia.embrapa.br/FontesHTML/CaprinoseOvinosdeCor te/CaprinosOvinosCorteNEBrasil/index.htm > Acesso em: 27 de abril de 2015.

SCARAMUZZI, R. J.; CAMPBELL, B. K.; DOWNING, J. A; KENDALL, N. R.; KHALID, M.; MUNOZ-GUTIERREZ, M.; SOMCHIT, A. A review of the effects of supplementary nutrition in the ewe on the concentrations of reproductive and metabolic hormones and the mechanisms that regulate folliculogenesis and ovulation rate. Reproduction Nutrition Development, v. 46, n. 4, p. 339-354, 2006.

SORMUNEN-CRISTIAN, R.; JAUHIAINEN, L. Effect of nutritional flushing on the productivity of Finnish Landrace ewes. Small Ruminant Research, v. 43, n. 1, p. 75-83, 2002. 
STAPLES, C. R.; BURKE, J. M.; THATCHER, W. W. Influence of supplemental fats on reproductive tissues and performance of lactating cows. Journal Dairy Science, v. 81, n.3, p. 856-871, 1998.

VALADARES FILHO, S. C.; MAGALHÃES, K. A.; ROCHA JUNIOR, V. R. MACHADO, P. A. S.; CHIZZOTI, M. L.; AMARAL, H. F.; CAPELLE, A. R. Tabelas brasileiras de composição de alimentos para bovinos. CQBAL 3.0. 3.ed. Viçosa: Suprema Gráfica, 2016. 329p.

VATANKHAH, M.; TALEBI, M.A.; ZAMANI, F. Relationship between ewe body condition score (BCS) at mating and reproductive and productive traits in LoriBakhtiari sheep. Small Ruminant Research, v. 106, n. 2-3, p. 105-109, 2012.

VILLAÇA, M.; EZEQUIEL, J. M. B.; KRONKA, S. N. Efeito de sementes oleaginosas inteiras e óleo de soja sobre a digestibilidade in vitro e os padrões ruminais de bezerros holandeses. Revista Brasileira de Zootecnia, v.28, n.3, p.654-659, 1999. 